\title{
Tratamento pré-germinativo de sementes de cebolinha com peróxido de hidrogênio
}

Objetivou-se estudar o tratamento pré-germinativo de sementes de cebolinha com diferentes concentrações de peróxido de hidrogênio. 0 experimento fo conduzido no laboratório de fisiologia vegetal pertencente à Universidade Federal de Campina Grande (UFCG). Os tratamentos foram distribuídos em delineamento inteiramente casualizado simples com cinco concentrações de peróxido de hidrogênio $(0,0 ; 0,015 ; 0,030 ; 0,045$ e 0,060 mM) e quatro repetições, totalizando 20 unidades experimentais. As sementes foram embebidas em recipientes de cor escura por 24 horas em temperatura ambiente. Adotou-se o método de germinação em substrato (papel germitest) umedecido com as soluções, a temperatura de $25^{\circ} \mathrm{C}$. Foi avaliado o sistema produtivo que incluiu o número de plântulas germinadas (NPG), comprimento das plântulas (CP), massa fresca das plântulas (MFP), massa seca das plântulas (MSP), porcentagens de germinação (\%G), índice de velocidade de germinação (IVG), tempo médio de germinação (TMG) e a velocidade média de germinação (VMG). As avaliações foram realizadas diariamente durante 12 dias após a instalação do teste. $O$ pré-tratamento das sementes com peróxido de hidrogênio influenciou positivamente no crescimento das plântulas de cebolinha. Diante dos resultados, recomenda-se o pré-tratamento das sementes de cebolinha com 0,036 mM de peróxido de hidrogênio.

Palavras-chave: Allium Fistulosum; Germinação; Espécies Reativas; H2O2.

\section{Pre-germinative treatment of hydrogen peroxide chive seeds}

\begin{abstract}
The objective was to study the pre-germination treatment chive seeds with different concentrations of hydrogen peroxide. The experiment was conducted at the plant physiology laboratory belonging to the Federal University of Campina Grande (UFCG). The treatments were distributed in a completely randomized design with five concentrations of hydrogen peroxide $(0.0,0.015,0.030,0.045$ and $0.060 \mathrm{mM})$ and four replications, totaling 20 experimental units. The seeds were soaked in dark colored containers for 24 hours at room temperature. It adopted the substrate moistened germination method (germitest paper) with the solutions at 25 ${ }^{\circ} \mathrm{C}$. The productive system that included the number of germinated seedlings (NPG), seedling length (CP), seedling fresh mass (MFP), seedling dry mass (MSP), germination percentages (\%G), speed index was evaluated, germination rate (IVG), average germination time (TMG) and average germination speed (VMG). Assessments were performed daily for 12 days after test installation. Pretreatment of seeds with hydrogen peroxide had a positive influence on the growth of chive seedlings. Given the results, it is recommended to pre-treat the chives seeds with $0.036 \mathrm{mM}$ hydrogen peroxide.
\end{abstract}

Keywords: Allium Fistulosum; Germination; Reactive Species; H2O2.

Topic: Uso de Recursos Naturais

Reviewed anonymously in the process of blind peer
Received: 10/08/2019

Approved: 28/09/2019
Barbara Davis Brito dos Santos (iD)

Universidade Federal de Campina Grande, Brasil http://lattes.cnpq.br/4374064087207806 http://orcid.org/0000-0003-3666-5867 barbara.brito90@hotmail.com

Semako Ibrahim Bonou

Universidade Federal de Campina Grande, Brasil http://lattes.cnpq.br/0278611065117108 bonouibrahim@gmail.com

\section{Rigoberto Moreira de Matos (iD)}

Universidade Federal de Campina Grande, Brasil http://lattes.cnpq.br/9976807429777592 http://orcid.org/0000-0003-3455-9876 rigobertomoreira@gmail.com
Patrícia Ferreira da Silva (iD

Universidade Federal de Campina Grande, Brasil http://lattes.cnpq.br/8146309314429987 http://orcid.org/0000-0002-4580-2336 patrycyafs@yahoo.com.br

João Henrique de Andrade Cabral (iD)

Universidade Federal de Campina Grande, Brasil http://lattes.cnpq.br/3675200615907308 http://orcid.org/0000-0001-9158-0394 jandrade.cabral@gmail.com

Raucha Carolina de Oliveira

Universidade Federal de Campina Grande, Brasil http://lattes.cnpq.br/5715119322580975 http://orcid.org/0000-0002-3517-8840 rauchaoliveira@gmail.com
José Dantas Neto (iD)

Universidade Federal de Campina Grande, Brasi http://lattes.cnpq.br/9137226205129315 http://orcid.org/0000-0003-0798-6717 zedantas1955@gmail.com

Vera Lucia Antunes de Lima (iD

Universidade Federal de Campina Grande, Brasi http://lattes.cnpq.br/5379077061489077 http://orcid.org/0000-0001-7495-6935 antuneslima@gmail.com

\section{Referencing this:}

SANTOS, B. D. B.; BONOU, S. I.; MATOS, R. M.; SILVA, P. F.; CABRAL, J. H. A.; OLIVEIRA, R. C.; DANTAS NETO, J.; LIMA, V. L. A.. Tratamento pré-germinativo de sementes de cebolinha com peróxido de hidrogênio. Revista Ibero Americana de Ciências Ambientais, v.10, n.5, p.307-313, 2019. DOI: http://doi.org/10.6008/CBPC21796858.2019 .005 .0027 


\section{INTRODUÇÃO}

A cebolinha (Allium fistulosum) é uma planta pertencente à família das Aliáceas, consumida em diferentes partes do mundo e comumente utilizada como condimento no Nordeste brasileiro (SOUZA et al., 2015). As plantas dessa espécie se caracterizam pelo intenso perfilhamento, formando touceira, as folhas são tubular-alongadas, macias e aromáticas (FILGUEIRA, 2008). Normalmente são consumidos as folhas e o bulbo da planta, os quais são ricos em vitaminas A, C e ferro, e o consumo desse vegetal estimula o apetite, auxilia a digestão e atua no combate à gripe e doenças das vias respiratórias (ZÁRATE et al., 2010).

Entretanto, as plantas estão expostas a ambientes adversos, com grande multiplicidade de fatores estressores (NAKAGAWA et al., 2018). E esses estresses ambientais podem afetar negativamente a germinação, crescimento e desenvolvimento das espécies de interesse econômico (ANDRADE et al., 2018). A região Nordeste é caracterizada pela irregularidade pluviométrica com grande variabilidade espacial e temporal das chuvas. A própria geologia do local, solos cristalinos, que compõem grande parte do semiárido brasileiro contribuem para que os corpos hídricos contenham altos níveis de sais (SOUZA et al., 2015).

Tanto o estresse salino, quanto o hídrico causam alterações nos processos fisiológicos e bioquímicos das plantas como, diminuição do teor relativo de água na folha e redução dos pigmentos fotossintéticos (KAUSHAL et al., 2016). Nesse sentido, a aplicação de peróxido de hidrogênio tem sido alternativa para minimizar os efeitos negativos dos estresses ambientais em sementes, cuja finalidade é o estímulo ao processo germinativo (HOSSAIN et al., 2015).

Além de melhorar a germinação e proteger as plântulas subsequentemente do estresse biótico e abiótico, nas sementes embebidas, muitos processos são desencadeados, modificações genéticas e bioquímicas, constituindo uma 'memória de estresse', na qual pode ser expressa durante outras fases do desenvolvimento da planta (WOJTYLA et al., 2016a).

O peróxido de hidrogênio atua como sinalizador para germinação com ação nas biomoléculas ABA e $\mathrm{GA}$, exercendo também forte controle na oxidação seletiva de proteínas e mRNA, reguladores chave para uma adequada germinação (WOJTYLA et al., 2016b). Segundo Sneideris et al. (2015) a exposição prévia das sementes por embebição com o peróxido de hidrogênio também controlada em soluções específica, possibilita a ocorrência de reações metabólicas pré-germinativas. Assim pergunta-se, o pré-tratamento com peróxido de hidrogênio irá afetar a germinação de sementes de cebolinhas?. Dada à relevância da temática, objetivou-se com este estudo avaliar o tratamento pré-germinativo de sementes de cebolinha com diferentes concentrações de peróxido de hidrogênio.

\section{MATERIAIS E MÉTODOS}

\section{Localização da área de estudo}

O experimento foi desenvolvido no laboratório de fisiologia vegetal pertencente à Universidade Federal de Campina Grande (UFCG), situada no município de Campina Grande/PB, sob as coordenadas geográficas de 70 13' 11" latitude Sul e 350 53' 31' de longitude Oeste e altitude de 550 m, conforme 
apresenta a Figura 1.

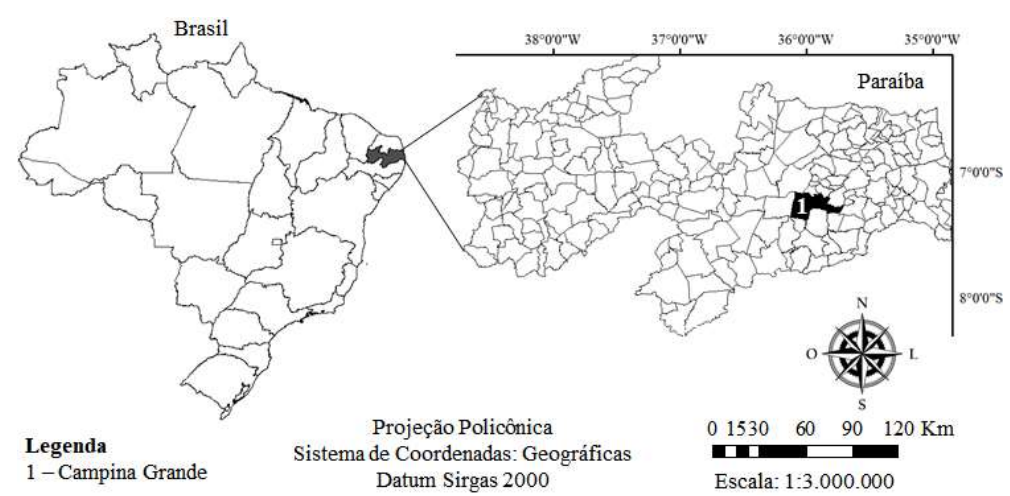

Figura 1: Localização do município de Campina Grande no estado da Paraíba.

No município de Campina Grande/PB o período chuvoso ocorre com maior intensidade de março a julho, onde as deficiências hídricas são concentradas de outubro a março, com maior disponibilidade hídrica de junho a julho, sendo a menor evapotranspiração potencial incidida no mês de agosto e máxima em dezembro, enquanto que a evaporação real possui picos de mínimas em novembro e de máximas em abril, e a temperatura média mensal atinge a máxima no mês de fevereiro e mínima no mês de julho (MEDEIROS et al., 2014).

O índice de umidade é $8,02 \%$, o de aridez $26,72 \%$ e o hídrico $18,70 \%$, sendo a fórmula climática C2SW conforme a classificação de Thornthwaite (1948), onde se trata de um clima subúmido, com ocorrência de moderada deficiência de água no verão, sendo o índice de aridez entre 16,7 e 33,3, mesotérmicos e com incidência de vegetação ao longo do ano. Enquanto que, conforme a classificação de Köppen, o município de Campina Grande/PB, possui o clima do tipo Bs'h (MEDEIROS et al., 2014).

\section{Condução do estudo}

No experimento foi realizado o teste de germinação conforme metodologia descrita nas regras para análise de sementes (MAPA, 2009). A semeadura das cebolinhas verdes foi realizada em substrato (papel germitest) umedecido com as soluções em quantidade equivalente a 2,5 vezes o seu peso. As sementes foram embebidas em recipientes de cor escura contendo $40 \mathrm{ml}$ de solução (Água mais peróxido de hidrogênio) nas concentrações de 0,0; 0,015; 0,030;0,045 e 0,065 mM e incubadas à temperatura ambiente por 24 horas. Após a semeadura foram feitos rolos com o material em estudo e em seguida, embalados em sacos plásticos para posterior colocação em estufa incubadora (BOD), a 25 ㄷ. Para cada tratamento, foram utilizadas 200 sementes, distribuídas em quatro repetições de 50 sementes.

\section{Variáveis analisadas}

Os cálculos das porcentagens de germinação (\%G), tempo médio de germinação (TMG), e a velocidade média de germinação (VMG) foram realizados conforme fórmulas citadas por Labouriau et al. (1976). As porcentagens de germinação (\%G) foram calculadas utilizando a Equação 1. 


$$
\% \mathrm{G}=\left(\frac{\mathrm{N}}{\mathrm{NS}}\right) * 100
$$

Em que: $\mathrm{N}$ - número de sementes germinadas ao final do teste; e NS - número de semente colocada para germinar.

O tempo médio de germinação (TMG) foi obtido conforme apresenta a Equação 2.

$$
\mathrm{TMG}=\frac{(\Sigma \mathrm{ni} * \mathrm{ti})}{\sum \mathrm{ni}}
$$

Em que: ni - número de sementes germinadas por dia; e ti - tempo de incubação, o TMG é expresso em dias. A velocidade média de germinação (VMG) foi determinada conforme expressa a Equação 3.

$$
\mathrm{VMG}=1 / \mathrm{t}
$$

Em que: $\mathrm{t}$ - tempo médio de germinação em dias, o VMG é expresso em dias.

$\mathrm{O}$ índice de velocidade de germinação (IVG) foi determinado de acordo com a metodologia proposta por Maguire (1962), conforme expressa a Equação 4.

$$
(\mathrm{IVG})=\sum_{\mathrm{i}=1}^{\mathrm{n}}\left(\frac{\mathrm{Ni}}{\mathrm{Di}}\right)
$$

Em que: IVG - índice de velocidade de germinação, adimensional; N1, N2... Ni = número de sementes germinadas na primeira contagem, segunda contagem... i-ésima contagem, respectivamente; D1 , D2... Di = número de dias na primeira contagem, segunda contagem... i-ésima contagem, respectivamente.

Ao fim do teste de germinação realizou-se análise de desenvolvimento das plântulas, onde foram analisados o número de plântulas germinadas (NPG), através de contagem direta; o comprimento das plântulas (CP), com auxílio de régua graduada; a massa fresca das plântulas (MFP), determinadas através de pesagem em balança; e massa seca das plântulas (MSP), obtida por meio de secagem da MFP em estufa de circulação forçada a $65^{\circ} \mathrm{C}$ e posteriormente pesada em balança de precisão de $0,01 \mathrm{~g}$ para obtenção da MSP.

\section{Análise estatística}

As variáveis foram analisadas estatisticamente pelo teste $F$, desdobrando-se as análises sempre que houver efeito significativo. O fator quantitativo relativo às concentrações de peróxido de hidrogênio foi analisado por meio de regressão polinomial (linear e quadrática) com auxílio do programa computacional Sisvar (FERREIRA, 2014).

\section{RESULTADOS E DISCUSSÃO}

O resumo da análise de variância para número de plantas germinadas (NPG), comprimento das plântulas (CP), massa fresca das plântulas (MFP), massa seca das plântulas (MSP), porcentagens de germinação (\%G), índice de velocidade de germinação (IVG), tempo médio de germinação (TMG) e a velocidade média de germinação (VMG) de sementes de cebolinha embebidas em peróxido de hidrogênio se encontram na Tabela 1.

Observa-se que não houve efeito das concentrações de peróxido de hidrogênio estudas sobre o número de plantulas germinadas, massa seca das plântulas, porcentagens de germinação, índice de velocidade de germinação, tempo médio de germinação e a velocidade média de germinação pelo teste $F$ ao nível de 1 e 5\%. No entanto, as concentrações de peróxido de hidrogênio influenciou o crescimento das plântulas de cebolinha (comprimento das plântulas e massa fresca das plântulas). 
Tabela 1: Resumo da análise de variância para as variáveis analisadas de sementes de cebolinha em função de diferentes concentrações de peróxido de hidrogênio.

\begin{tabular}{|c|c|c|c|c|c|c|c|c|c|}
\hline \multirow[t]{2}{*}{ FV } & \multirow[t]{2}{*}{ GL } & \multicolumn{8}{|c|}{ 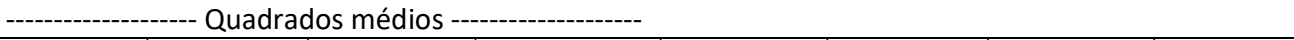 } \\
\hline & & NPG & $\begin{array}{l}\mathrm{CP} \\
(\mathrm{cm})\end{array}$ & $\begin{array}{l}\text { MFP } \\
\text { (g) }\end{array}$ & $\begin{array}{l}\text { MSP } \\
\text { (g) }\end{array}$ & $\begin{array}{l}\text { \%G } \\
\text { (\%) }\end{array}$ & IVG & $\begin{array}{l}\text { TMG } \\
\text { (Dias) }\end{array}$ & $\begin{array}{l}\text { VMG } \\
\text { (Dias) }\end{array}$ \\
\hline $\mathrm{CP}$ & 4 & $4,12^{\text {ns }}$ & $2,15^{* *}$ & $0,012^{* *}$ & $0,000027^{n s}$ & $16,50^{\text {ns }}$ & $0,10^{\text {ns }}$ & $0,055^{\mathrm{ns}}$ & $0,00028^{n s}$ \\
\hline Eq. Linear & - & $4,90^{\text {ns }}$ & $3,08^{* *}$ & $0,011^{*}$ & $0,000024^{\mathrm{ns}}$ & $19,60^{\text {ns }}$ & $0,10^{\text {ns }}$ & $0,025^{\mathrm{ns}}$ & $0,00030^{\text {ns }}$ \\
\hline $\begin{array}{l}\text { Eq. } \\
\text { Quadrática }\end{array}$ & - & $0,00^{\text {ns }}$ & $4,40^{* *}$ & $0,037^{* *}$ & $0,000058^{\text {ns }}$ & $0,00^{\text {ns }}$ & $0,02^{\text {ns }}$ & $0,035^{\mathrm{ns}}$ & $0,00014^{\text {ns }}$ \\
\hline Repetição & 3 & 11,93 & 0,10 & 0,005 & 0,000018 & 47,73 & 0,95 & 0,045 & 0,00034 \\
\hline Resíduo & 12 & 4,72 & 0,15 & 0,001 & 0,000023 & 18,90 & 0,79 & 0,098 & 0,00089 \\
\hline CV (\%) & - & 5,37 & 8,59 & 9,47 & 14,42 & 5,37 & 6,76 & 9,28 & 10,08 \\
\hline $\begin{array}{l}\text { Média } \\
\text { geral }\end{array}$ & - & 40,50 & 4,58 & 0,41 & 0,033 & 81,00 & 13,19 & 3,38 & 0,30 \\
\hline
\end{tabular}

FV - Fonte de variação; GL - Grau de liberdade; CP - Concentrações de peróxido; CV - Coeficiente de variação; ${ }^{\text {ns }}$ - Não significativo em nível de 0,05 de probabilidade pelo Teste $\mathrm{F} ;{ }^{*} ;{ }^{* *}$ Significativo em nível de 0,05 e 0,01 de probabilidade, respectivamente, pelo Teste $\mathrm{F}$.

Resultados semelhantes foram encontrados por Gondim (2012), ao analisar os efeitos do peróxido de hidrogênio sobre a germinação e aclimatação de plantas de milho com níveis de salinidade, não observou diferença significativa na porcentagem de germinação nas concentrações de 100 mM e 500 mM de peróxido de hidrogênio. No entanto, o pré-tratamento de sementes de arroz com peróxido de hidrogênio embebido com concentração de $10 \mathrm{mM}$, resultou em aumento da velocidade e porcentagem de germinação (CHEN et al., 2016). Panngom et al. (2018) trabalhando com sementes de cenoura e coentro embebidos em 25 e 50 mM observaram incremento na atividade da germinação e crescimento inicial de plântulas.

Barba-Espin et al. (2011) mostraram que a pré-embebição de sementes de Pisum sativum, em solução de peróxido de hidrogênio, nas concentrações de 10 e 20 mM, aumenta a velocidade de germinação, com até 12 horas de embebição em condições de $25^{\circ} \mathrm{C}$ e no escuro, aproximadamente $70 \%$ das sementes pré-embebidas germinaram e quando não tratadas esse valor decresce para no máximo 8\% de germinação para igual horas observadas.

O mesmo acontece para variáveis como peso fresco e comprimento das plântulas o que evidencia a significância desse tratamento. Em tais estudos reforça que houve variabilidade na concentração responsiva de peróxido de hidrogênio em função da espécie, isso demostra que há uma faixa crítica onde ocorre maior probabilidade de resposta, dependendo da espécie e do método empregado (WOJTYLA et al., 2016b). Em relação às variáveis comprimento das plântulas (CP) e massa fresca das plântulas (MFP) houve diferença significativa entre os tratamentos conforme os modelos quadráticos (Figura 2).

Conforme os gráficos observa-se que a concentração de peróxido de hidrogênio que evidenciou o maior comprimento de plântulas foi a de $0,037 \mathrm{mM}$, cerca de $5,21 \mathrm{~cm}$. Em relação à massa fresca das plântulas a concentração de $0,035 \mathrm{mM}$ proporcionou a maior MFP $(0,46 \mathrm{~g})$. 0 peróxido de hidrogênio é um composto reativo do oxigênio que atua na parede celular da semente afrouxando as ligações por processos degenerativos, devido à propriedade de serem ou gerarem radicais livres favorecendo ao desenvolvimento das estruturas vegetativas (SALISBURY et al., 2012).

Resultados semelhantes foram encontrados por Oliveira (2016) estudando a germinação e estabelecimento inicial in vitro de Lavandula angustifólia com pré-tratamento em peróxido de hidrogênio 
resultou em valores superiores para comprimento das plântulas, número de folhas e massa fresa. Em experimento realizado por Çavusoglu et al. (2010) com sementes de cevada tratadas com peróxido de hidrogênio obtiveram comprimento radicular cerca de duas vezes superior em relação à testemunha (água destilada). Esses resultados demostram que o peróxido de hidrogênio favorece o desenvolvimento de estruturas vegetativas.

(A)

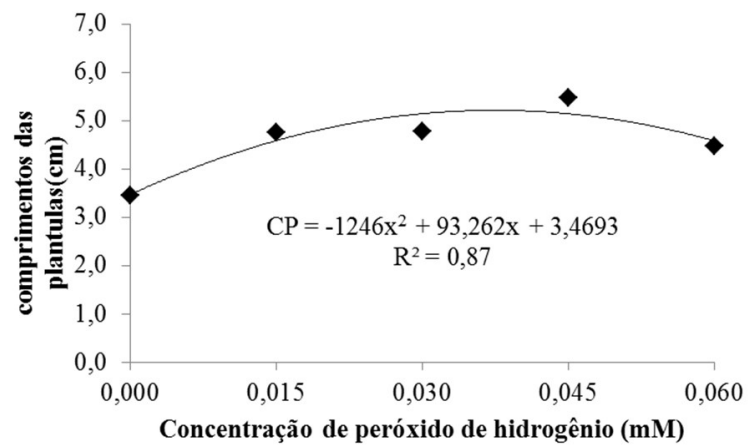

(B)

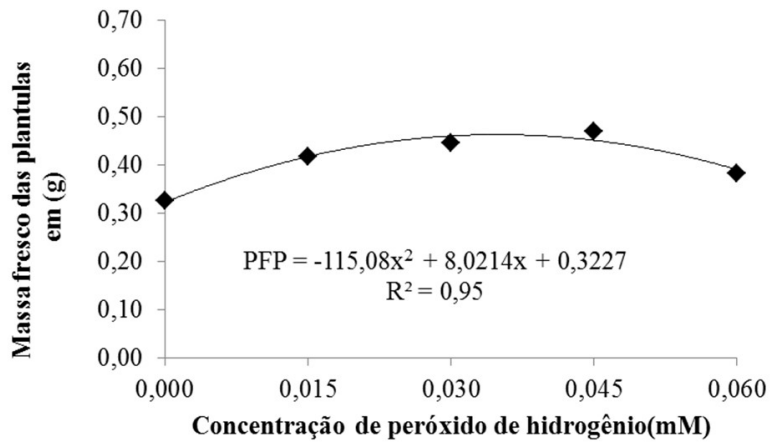

Figura 2: Comprimento das plântulas (A) e massa fresca das plântulas (B) de cebolinha em função da concentração de peróxido de hidrogênio.

\section{CONCLUSÕES}

O pré-tratamento das sementes com peróxido de hidrogênio influenciou positivamente no crescimento das plântulas de cebolinha. Diante dos resultados, recomenda-se o pré-tratamento das sementes de cebolinha com 0,036 mM de peróxido de hidrogênio.

AGRADECIMENTOS: a Coordenação de Aperfeiçoamento de Pessoal de Nível Superior (CAPES) e ao Conselho Nacional de Desenvolvimento Científico e Tecnológico (CNPq), pela concessão das bolsas de pós-graduação.

\section{REFERÊNCIAS}

ANDRADE, C. A.; SOUZA, K. R. D.; OLIVEIRA, S. M.; SILVA, D. M.; ALVES, J. D.. Hydrogen peroxide promotes the tolerance of soybeans to waterlogging. Science Horticulture, v.232, p.40-45, 2018. DOI:

http://doi.org/10.1016/j.scienta.2017.12.048

BARBA-ESPÍN, G.; DIAZ-VIVANCOS, P.; JOB, D.; BELGHAZI, M.; JOB, C.; HERNÁNDEZ, J. A.. Understanding the role of $\mathrm{H}_{2} \mathrm{O}_{2}$ during pea seed germination: a combined proteomic and hormone profiling approach. Plant, cell \& environment, Glasgow, v.34, n.11, p.1907-1919, 2011. DOI: http://doi.org/10.1111/j.1365-3040.2011.02386.x

ÇAVUSOGLU, K; KABAR, K.. Effects of hydrogen peroxide on the germination and early seedling growth of barley under $\mathrm{NaCl}$ and high temperature stresses. EurAsian Journal of BioSciences, Izmir, v.4, n.9, p.0-79, 2010. DOI: http://doi:10.5053/ejobios.2010.4.0.9

CHEN, B. X.; LI, W. Y.; GAO, Y. T.; CHEN, Z. J.; ZHANG, W. N.; LIU, Q. J.; CHEN, Z.. Involvement of polyamine oxidaseproduced hydrogen peroxide during coleorhiza-limited germination of rice seeds. Frontiers in plant science,
Rockville, v.7, p.1219, 2016. DOI:

http://doi.org/10.3389/fpls.2016.01219

FERREIRA, D. F.. SISVAR: A Guide for its Bootstrap procedures in multiple comparisons. Ciência e Agrotecnologia, Lavras, v.38, n.2, p.109-112, 2014. DOI: http://dx.doi.org/10.1590/S1413-70542014000200001

FILGUEIRA, F.. Novo manual de olericultura: agrotecnologia moderna na produção e comercialização de hortaliças. Viçosa: UFV, 2008.

GONDIM, F. A.. Pré-tratamento foliar com $h_{2} \mathrm{O}_{2}$ como estratégia para minimizar os efeitos deletérios da salinidade em plantas de milho. Tese (Doutorado em bioquímica) - Universidade Federal do Ceará, Fortaleza, 2012.

HOSSAIN, M. A.; BHATTACHARJEE, S.; ARMIN, S. M.; QIAN, P.; XIN, W.; LI, H. Y.; BURRITT, D. J.; FUJITA, M.; TRAN, L. P.. Hydrogen peroxide priming modulates abiotic oxidative stress tolerance: insights from ROS detoxification and scavenging. Frontiers in plant science, Rockville, v.6, p.420, 
2015. DOI: http://doi.org/10.3389/fpls.2015.00420

KAUSHAL, M.; WANI; S. P.. Rhizobacterial-plant interactions: strategies ensuring plant growth promotion under drought and salinity stress. Agriculture, Ecosystems \& Environment, v.231, p.68-78, 2016. DOI:

http://doi.org/10.1016/j.agee.2016.06.031

LABOURIAU, L. G.; VALADARES, M. E. B.. On the germination of seeds Calotropis procera (Ait.) Ait.f. Anais da Academia Brasileira de Ciências, Brasília, v.48, n.2, p.263-284, 1976.

MAGUIRE, J. D.. Speed of germination aid in selection and evaluation for seedling emergence and vigor. Crop Science, Madison, v.2, n.2, p.176-77, 1962. DOI: http://dx.doi.org/10.2135/cropsci1962.0011183X000200020 $\underline{033 x}$

MAPA. Ministério da Agricultura, Pecuária e Abastecimento. Regras para análise de sementes. Brasília: MAPA, 2009.

MEDEIROS, R. M.; FRANCISCO, P. R. M.; BORGES, C. K.; GOMES FILHO, M. F.. Caracterização e classificação climática da cidade de Campina Grande/PB. In: CONGRESSO TÉCNICO CIENTÍFICO DA ENGENHARIA E DA AGRONOMIA. Anais. Teresina: CONTECC, 2014. p.5.

NAKAGAWA, A. C.; ITOYAMA, H.; ARIYOSHI, Y.; ARIO, N.; TOMITA, Y.; KONDO, Y.; ISHIBASHI, Y.. Drought stress during soybean seed filling affects storagecompounds through regulation of lipid and protein metabolism. Acta Physiologiae Plantarum, Springer, v.40, p.111, 2018. DOI: http://doi.org/10.1007/s11738-018-2683-y

OLIVEIRA, R. C.. Germinação e estabelecimento inicial in vitro de Lavandula angustifolia. Dissertação (Mestrado em Agronomia) - Universidade Federal de Uberlândia, Uberlândia, 2016.

PANNGOM, K.; CHUESAARD, T.; TAMCHAN, N.; JIWCHAN, T.;
SRIKONGSRITONG K.; PARK, G.. Comparative assessment for the effects of reactive species on seed germination, growth and metabolisms of vegetables. Science Horticulture, v.227, p.85-91, 2018. DOI:

http://doi:org/10.1016/j.scienta.2017.09.026

SALISBURY, F. B.; ROSS, C. W.. Fisiologia das plantas. São Paulo: Cengage Learning, 2012.

SNEIDERIS, L. C.; GAVASSI, M. A.; CAMPOS, M. L.; D'AMICODAMIAO, V.; CARVALHO, R. F.. Effects of hormonal priming on seed germination of pigeon pea under cadmium stress. Anais da Academia Brasileira de Ciências, Rockville, v.87, p.1847-1852, 2015. DOI: http://doi:org/10.1590/0001 3765201520140332

SOUZA, B. P.; SIMÕES, A. C.; ALVES, G. K. E. B.; FERREIRA, R. L. F.; ARAÚJO NETO, S. E.. Produtividade e rentabilidade de cebolinha orgânica sob diferentes densidades de plantio e métodos de colheita. Enciclopédia Biosfera, Goiânia, v.11, n.21, p.1576-1585, 2015.

WOJTYLA, L.; LECHOWSKA, K.; KUBALA, S.; GARNCZARSKA, $M$.. Different modes of hydrogen peroxide action during seed germination. Frontiers in plant science, Rockville, v.7, p.66, 2016a. DOI: http://doi.org/10.3389/fpls.2016.00066

WOJTYLA, L.; LECHOWSKA, K.; KUBALA, S.; GARNCZARSKA, M.. Molecular processes induced in primed seeds-increasing the potential to stabilize crop yields under drought conditions. Journal of plant physiology, Rockville, v.203, p.116-126, 2016b. DOI: http://doi:org/10.1016/j.jplph.2016.04.008

ZÁRATE, N. A.; MATTE, L. C.; VIERA, M. C.; GRACIANO, J. D.; HEID, D. M.; HELMICH, M.. Amontoas e cobertura do solo com cama-de-frango na produção de cebolinha, com duas colheitas. Acta Scientiarum Agronomy, Maringá, v.32, n.3, p.449-454, 2010. DOI:

http://dx.doi.org/10.4025/actasciagron.v32i3.4379

A CBPC - Companhia Brasileira de Produção Científica (CNPJ: 11.221.422/0001-03) detém os direitos materiais desta publicação. Os direitos referem-se à publicação do trabalho em qualquer parte do mundo, incluindo os direitos às renovações, expansões e disseminações da contribuição, bem como outros direitos subsidiários. Todos os trabalhos publicados eletronicamente poderão posteriormente ser publicados em coletâneas impressas sob coordenação da Sustenere Publishing, da Companhia Brasileira de Produção Científica e seus parceiros autorizados. Os (as) autores (as) preservam os direitos autorais, mas não têm permissão para a publicação da contribuição em outro meio, impresso ou digital, em português ou em tradução. 